KeMAS 16 (2) (2020) 249-255
Jirnal Kesehatan Masyarakat

\title{
Insomnia and Quality of Life in the Elderly: WHOQOL-BREF and WHOQOL-OLD Indonesian Version
}

\author{
Binar Cinta $^{1 \bowtie}$, Sharon Gondodiputro ${ }^{2}$, Santi Andayani ${ }^{3}$ \\ ${ }^{1}$ Faculty of Medicine, Padjadjaran University, Bandung, Indonesia \\ ${ }^{2}$ Department of Public Health, Faculty of Medicine, Padjadjaran University, Bandung, Indonesia \\ ${ }^{3}$ Department of Psychiatry, Faculty of Medicine, Padjadjaran University, Bandung, Indonesia
}

\section{Article Info \\ Article History: \\ Submitted January 2020 \\ Accepted January 2020 \\ Published November 2020 \\ Keywords: \\ Elderly, insomnia, qual- \\ ity of life, WHOQOL- \\ BREF, WHOQOL-OLD \\ DOI \\ https://doi.org/10.15294/ \\ kemas.v16i2.22895}

\begin{abstract}
In Indonesia, the Elderly are someone who has reached the age of 60 years old and over. Along with the aging, there will be changes in sleep pattern and awakening process so that insomnia will appear. Insomnia can cause decrease in quality of life. The aim of this study was to analyze the relationship between insomnia and quality of life in elderly which measured by WHOQOL-BREF and WHOQOL-OLD Indonesian version. The qquantitative analytical cross-sectional study had been carried out to 60 elderly from 6 Public Health Centers in Bandung City, West Java, Indonesia. This study was conducted from August to November 2019. Insomnia was measured by Insomnia Severity Index and quality of life was measured by WHOQOL-BREF and WHOQOL-OLD Indonesian version. The Spearman correlation test was used for data analysis. This study discovered that the proportion of insomnia in the elderly was 36,7\%(95\%ci:24.5\%-48.9\%). The ccorrelation coefficient between insomnia and quality of life was -0,386 (WHOQOL-BREF) and $-0,302$ (WHOQOL-OLD). It can be concluded that the proportion of insomnia in the elderly is high and there is a correlation between insomnia and quality of life even though the correlation is weak.
\end{abstract}

\section{Introduction}

Aging will cause changes in sleep patterns and awakening process.(Sateia, 2010) Changes in sleep patterns and awakening process can cause one of the sleep disorders namely insomnia. Insomnia is a subjective complaint in the form of difficulty starting to sleep, difficulty maintaining sleep, and waking up too early which appears at least three nights a week and lasts for three months (Rodriguez, Dzierzewski, Alessi, 2015). Insomnia can cause several consequences such as difficulty concentrating, mood disorders, fatigue, anxiety about sleep patterns, increasing the risk of falling, and difficulties both physically and psychologically. Difficulty concentrating, fatigue, physical difficulties, and psychological difficulties can affect the quality of life of the elderly (Rodriguez, Dzierzewski, Alessi, 2015).

According to World Health Organization (WHO), quality of life (QoL) is an individual perception about their position in life, in the context of culture and values in their surrounding environment, as well as with the goals, expectations, standards and attention of each individual.(Soósová, 2016) A study conducted by I. Uchmanowicz discovered that sleep problems had a significant negative impact on the QoL. (Uchmanowicz et al., 2019)

One of the instruments to measure insomnia that frequently used is the Insomnia Severity Index (ISI). This instrument composes of seven items that assess the nature, severity, and impact of insomnia. This instrument 
consists of several items which are the severity of sleep onset, sleep maintenance, waking up too early, dissatisfaction with sleep, the relationship between sleep disturbance and function during the day, sleep disturbance seen by others, and difficulties arising from sleep disorders.(Morin et al., 2011)it often remains unrecognized and untreated. Brief and valid instruments are needed both for screening and outcome assessment. This study examined psychometric indices of the Insomnia Severity Index (ISI

The World Health Organization developed several instruments for measuring the quality of life which is the World Health Organization Quality of Life (WHOQOL)-100 (WHOQOL-100), World Health Organization Quality of Life (WHOQOL)-BREF (WHOQOL-BREF), and specifically for the elderly is World Health Organization Quality of Life (WHOQOL)-OLD (WHOQOL-OLD) in addition to WHOQOL-100 or WHOQOLBREF instruments. The Indonesian version of the WHOQOL-BREF instrument consists of 24 items covering four dimensions which are physical aspects, psychological aspects, social aspects, and environmental aspects.(Purba et al., 2018) The Indonesian version of the WHOQOL-OLD consists of 24 items covering six dimensions which are sensory ability; autonomy; past, present and future activities; participation; death and dying; and intimacy. (Gondodiputro et al., 2019)

Studies on the correlation between insomnia and QoL using both WHOQOLBREF and WHOQOL-OLD Indonesian version has not been carried out, therefore, the aim of this study was to analyze the correlation between insomnia and quality of life in elderly as measured using the Indonesian version of WHOQOL-BREF and WHOQOL-OLD.

\section{Method}

A quantitative analytic study with a crosssectional approach had been carried out from August 2019 to November 2019 in Bandung City, West Java, Indonesia. The population of this study was the elderly who were aged $>=60$ years and who came for treatment at the Public Health Centers (Puskesmas). The inclusion criteria in this study were respondents aged $>=60$ years, both men and women, came to
Public Health Center for treatment, would participate in this study, were able to speak and hear well, did not suffer from cognitive impairment as measured by a mini-cog test , and did not suffer from severe psychotic disorders as measured by MINI-Psychotic Symptoms. The exclusion criteria were the respondents who were not able to fill all the questionnaires until the end. The total sample needed in this study was 60 respondents; therefore 6 from 80 Public Health Centers were selected using random number by the help of a computer. The respondents were taken from each Public Health Center using a consecutive sampling technique. This study was approved by the Ethics Commission of Padjadjaran University and The Bandung Municipality Health Office. The variables studied were insomnia and quality of life. Insomnia was measured using the Insomnia Severity Index (ISI) consisted of seven items, which were the severity of sleep onset, sleep maintenance, waking up too early, dissatisfaction with sleep, the relationship between sleep disturbance and function during the day, sleep disturbance seen by others, and difficulty which arises from sleep disorders. Each item was answered using a Likert Scale from zero to four. Zero point indicated no problems and four points indicated very severe problems. The total value of each item in this questionnaire was 0 to 28 . The aassessment of insomnia status was 0-7: no insomnia; 8-14: sub-threshold insomnia; 15-21: moderate insomnia; and 22-28: severe insomnia (Morin et al., 2011) it often remains unrecognized and untreated. Brief and valid instruments are needed both for screening and outcome assessment. This study examined psychometric indices of the Insomnia Severity Index (ISI).

Quality of life was measured using The Indonesian version of The WHOQOL-BREF and WHOQOL-OLD. The WHOQOL-BREF instrument was a questionnaire consisted of 26 items, two of them assess quality of life and overall health, 24 items consisted of four dimensions which were physical health (7 items), psychological (6 items), social relations (3 items), and environment (8 items). (Purba et al., 2018) The WHOQOL-OLD instrument was a questionnaire consisting of 24 items with six dimensions, each dimension contained four 
items. The six dimensions were sensory ability, independence, past activities, present, past and future activities, participation, death and dying, and intimacy.(Gondodiputro et al., 2019) The score of each item both in WHOQOLBREF and WHOQOL-OLD instruments used a Likert scale from one to five. After the questionnaire was filled out by the respondents, each dimension was added up, then the total score of each dimension was converted to a scale from zero to one hundred (World Health Organization, 2006).

Prior to data collection, selected respondents were given an explanation of the objectives, procedures, and risks of this study. After respondent agrees to participate in this study, they signed the informed consent form. The data collection was carried out by guiding the respondents to answer the statements listed in the questionnaire of the ISI, WHOQOLBREF and WHOQOL-OLD.

The categorical data from ISI scores and scores from each domain at both WHOQOLBREF and WHOQOL-OLD, were transformed into interval data in the form of logit unit values using the Rasch Modelling, assisted by the Winstep program version 3.73.(Boone, 2016) The logit unit value obtained was tested for normality using Kolmogorov-Smirnov, assisted by the $\mathrm{IBM}^{\otimes} \mathrm{SPSS}^{\oplus}$ version 22.0 program. The result of the normality test indicated that the transformed data were not normally distributed so the correlation test used in the study was the Spearman correlation test. The interpretation of the correlation coefficient was $0.00-0.10$ : there was no correlation; $0.10-0.39$ : weak correlation; 0.40-0.69: moderate correlation; 0.70-0.89: strong correlation; and 0.90-1.00: very strong correlation (Schober \& Schwarte, 2018). If the $\mathrm{p}$ value $<0.05$ indicates there is a significant relationship between insomnia and quality of life.

\section{Result and Discussion}

The study on the correlation between insomnia and quality of life in elderly had been carried out to 60 respondents from 6 Puskesmas in Bandung. This study discovered that $81.7 \%$ of respondents were aged $60-70$ years, $66.7 \%$ were female, $73.3 \%$ were married, $41.7 \%$ had elementary school education and below, and $75 \%$ did not work. Insomnia is a sleep disorder that often occurs in the elderly (El-Gilany et al., 2017; Suzuki et al., 2017). The prevalence of insomnia in elderly varies, and is higher than in adults (Suzuki, Miyamoto, Hirata, 2017). A study conducted by Woo Jung Kim et al (2017) found the prevalence of insomnia is $32.4 \%$ (Kim et al., 2017). A study conducted in Nepal, found a prevalence of insomnia is $40.6 \%$ (Chhantyal, Rekha, 2017). Our study discovered that the

Table 1, Respondent Characteristics and Insomnia

\begin{tabular}{|c|c|c|c|c|c|}
\hline \multirow{2}{*}{ No. } & \multirow{2}{*}{ Characteristic } & \multicolumn{2}{|c|}{ Not Insomnia } & \multicolumn{2}{|c|}{ Insomnia } \\
\hline & & $\mathbf{n}$ & $\%$ & $\mathbf{n}$ & $\%$ \\
\hline \multirow[t]{3}{*}{1.} & Age & & & & \\
\hline & $60-70$ years old & 31 & 81.6 & 18 & 81.8 \\
\hline & >70 years old & 7 & 18.4 & 4 & 18.2 \\
\hline \multirow[t]{3}{*}{2.} & Gender & & & & \\
\hline & Male & 14 & 36.8 & 6 & 27.3 \\
\hline & Female & 24 & 63.2 & 16 & 72.7 \\
\hline \multirow[t]{3}{*}{3.} & Marital Status & & & & \\
\hline & Married & 30 & 78.9 & 14 & 63.6 \\
\hline & Divorced & 8 & 21.2 & 8 & 36.4 \\
\hline \multirow[t]{5}{*}{4.} & Education & & & & \\
\hline & Elementary School & 12 & 31.6 & 13 & 59.1 \\
\hline & Junior High School & 13 & 34.2 & 3 & 13.6 \\
\hline & Senior High School & 7 & 18.4 & 6 & 27.3 \\
\hline & $>$ Senior High School & 6 & 15.8 & 0 & 0,0 \\
\hline \multirow[t]{3}{*}{5.} & Profession & & & & \\
\hline & Unemployed & 29 & 76.3 & 16 & 72.7 \\
\hline & Employed & 9 & 23.7 & 6 & 27.3 \\
\hline
\end{tabular}

Source: Primary Data, 2019 
Table 2, Severity Level of Sleep Disorders

\begin{tabular}{llllllll}
\hline No. Sleep Disorders & $\begin{array}{l}\text { None } \\
\mathrm{n}(\%)\end{array}$ & $\begin{array}{l}\text { Low } \\
\mathrm{n}(\%)\end{array}$ & $\begin{array}{l}\text { Moderate } \\
\mathrm{n}(\%)\end{array}$ & $\begin{array}{l}\text { Severe } \\
\mathrm{n}(\%)\end{array}$ & $\begin{array}{l}\text { Very } \\
\text { Severe } \\
\mathrm{n}(\%)\end{array}$ & $\begin{array}{l}\text { Total } \\
\mathrm{n}(\%)\end{array}$ \\
\hline $\begin{array}{l}\text { 1. } \\
\begin{array}{l}\text { Difficulty falling } \\
\text { asleep }\end{array}\end{array}$ & $41(68.3)$ & $6(10.0)$ & $5(8.3)$ & $4(6.7)$ & $4(6.7)$ & $60(100.0)$ \\
$\begin{array}{l}\text { Difficulty staying } \\
\text { asleep }\end{array}$ & $32(53.3)$ & $6(10.0)$ & $10(16.7)$ & $8(13.3)$ & $4(6.7)$ & $60(100.0)$ \\
$\begin{array}{l}\text { Waking up earlier } \\
\text { than usual }\end{array}$ & $46(76.7)$ & $2(3.3)$ & $4(6.7)$ & $6(10.0)$ & $2(3.3)$ & $60(100.0)$ \\
\hline
\end{tabular}

Source: Primary Data, 2019

proportion of insomnia in the elderly was 22 out of 60 respondents $(36.7 \%$, 95\% CI:24.5\%$48.9 \%)$. The prevalence of insomnia is higher in elderly than in general population. Not all of the elderly seek for a professional help, made it under-diagnosed and under-treated.(Mukku et al., 2018) Moreover, there are some of the important misconceptions about insomnia in elderly, among others:

"reduced sleep is a normal aging phenomenon; reduced sleep in elderly is due to lack of any specific reason; elderly generallysleep during daytime, so they do not sleep at night; sleep problems in the elderly is a trivial issue; insomnia in the elderly does not require any specific professional help; insomnia in elderly just requires medicine prescription for few days; insomnia in elderly is always due to physical illness and elderly cannot sleep without sleeping pills." (Mukku et al., 2018)

From 22 respondents who experienced insomnia, 14 respondents experienced subthreshold insomnia, 7 respondents experienced moderate insomnia, and only 1 respondent experienced severe insomnia. It appeared that the majority of respondents who experienced insomnia were aged 60-70 years, female, had a junior high school education or below, married, and not working.(Table 1)

The incidence of insomnia in the elderly is related to the presence of comorbidities both physically and mentally, the use of drugs, and changes in sleep patterns (El-Gilany et al.,
2017; Suzuki et al., 2017). Changes in sleep patterns occur due to increased time spent in bed, awakening at night, as well as taking a nap.(Uchmanowicz et al., 2019) In the elderly, deeper stages of sleep which is stage three or slow wave sleep and REM stage lasts for a shorter period of time, whereas lighter sleep lasts for a longer period of time.(Uchmanowicz et al., 2019) Aging process also affects circadian rhythm. (Mattis \& Sehgal, 2016; Miner \& Kryger, 2017). The impact of the changes of the circadian rhythm is the occurrence of insomnia, consists of difficulty starting sleep, difficulty maintaining sleep, and waking up too early which appears at least three nights a week and lasts for three months (Rodriguez, Dzierzewski, Alessi, 2015).

Sleep disorders detected by The ISI questionnaire, in the form of three symptoms, namely difficulties in falling asleep, in staying asleep, and waking up earlier than usual. This study discovered that, as many as 10 elderly (16.7\%) had difficulty in staying asleep with a 'moderate' severity and as many as 6 elderly (10.0\%)hadwokenup earlier thanusual(Table2).

The sleep disorders can arise with more than one symptom. This study revealed that the proportion of the elderly who experienced two sleep symptoms $(20.0 \%)$ was higher than the elderly who experienced one symptom (18.3\%) or three symptoms (15.0\%). The most common sleep symptoms that occur together were the difficulty falling asleep and difficulty staying asleep (66.7\%). 
Table 3, Number of Symptoms on Sleep Disorders

\begin{tabular}{|c|c|c|c|}
\hline No. & Symptoms & $\mathrm{n}=60$ & $\%$ \\
\hline 1. & No symptom & 28 & 46.7 \\
\hline \multirow[t]{4}{*}{2.} & One symptom & 11 & 18.3 \\
\hline & $\begin{array}{l}\text { Difficulty falling } \\
\text { asleep }\end{array}$ & 1 & 9.1 \\
\hline & $\begin{array}{l}\text { Difficulty staying } \\
\text { asleep }\end{array}$ & 9 & 81.8 \\
\hline & $\begin{array}{l}\text { Waking up earlier } \\
\text { than usual }\end{array}$ & 1 & 9.1 \\
\hline \multirow[t]{4}{*}{3.} & Two symptoms & 12 & 20.0 \\
\hline & $\begin{array}{l}\text { Difficulty falling } \\
\text { asleep and difficulty } \\
\text { staying asleep }\end{array}$ & 8 & 66.7 \\
\hline & $\begin{array}{l}\text { Difficulty falling } \\
\text { asleep and waking up } \\
\text { earlier than usual }\end{array}$ & 1 & 8.3 \\
\hline & $\begin{array}{l}\text { Difficulty staying } \\
\text { asleep and waking up } \\
\text { earlier than usual }\end{array}$ & 3 & 25 \\
\hline 4. & Three symptoms & 9 & 15.0 \\
\hline
\end{tabular}

Source: Primary Data, 2019
Insomnia in elderly can have a negative effect on sleep quality that causes fatigue during the day, cognitive impairment, decreased physical and psychological health, and decreased quality of life (El-Gilany et al., 2017). Our study discovered that the median score of the four dimensions of the WHOQOL-BREF in the respondents who experienced insomnia was lower than the median score in the respondents who did not experience insomnia.(Table 4)

This study discovered that the median score from the dimensions of sensory ability; past, present and future activities; death and dying in the respondents who experience insomnia was lower than the respondents who did not experience insomnia, whereas in the domain of autonomy; participation; and intimacy, the median score both for respondents who did not experience insomnia and who experienced insomnia was equal.

Correlation test was conducted to analyze the correlation between insomnia and quality of life in elderly. This study discovered that there was a negative correlation between insomnia and quality of life using WHOQOLBREF, but the correlation was weak $(-0,386)$. In the physical domain, the correlation was moderate $(-0,518)$. Negative correlation also occurred between insomnia and quality of life using WHOQOL-OLD with weak correlation

Table 4, Insomnia and Quality of Life Score in Elderly using WHOQOL-BREF

\begin{tabular}{lllll}
\hline & \multicolumn{2}{l}{ WHOQOL-BREF } & \\
\cline { 2 - 4 } & Physical & Psychological & Social & Environment \\
\hline Not Insomnia $(\mathrm{n}=38)$ & 69 & 69 & 69 & 69 \\
Median & 38 & 44 & 44 & 56 \\
Minimum & 88 & 81 & 75 & 81 \\
Maximum & & & & \\
Insomnia (n=22) & & & & \\
Median & 56 & 59.5 & 56 & 63 \\
Minimum & 38 & 44 & 25 & 38 \\
Maximum & 81 & 88 & 100 & 94 \\
Source: Primary Data, 2019 & & & &
\end{tabular}




\begin{tabular}{|c|c|c|c|c|c|c|c|c|}
\hline & \multicolumn{8}{|c|}{ WHOQOL-OLD } \\
\hline & $\begin{array}{l}\text { Sensory } \\
\text { Ability }\end{array}$ & Autonomy & $\begin{array}{l}\text { Past, } \\
\text { present, } \\
\text { and future } \\
\text { activities }\end{array}$ & Participation & \multicolumn{2}{|c|}{$\begin{array}{l}\text { Death and } \\
\text { Dying }\end{array}$} & \multicolumn{2}{|c|}{ Intimacy } \\
\hline \multicolumn{9}{|c|}{$\begin{array}{l}\text { Not Insomnia } \\
(\mathrm{n}=38)\end{array}$} \\
\hline Median & 87.5 & 62.5 & 68.75 & 68.75 & 81.25 & \multicolumn{3}{|c|}{75} \\
\hline Minimum & 56.25 & 50 & 31.25 & 50 & 25 & \multicolumn{3}{|c|}{12.5} \\
\hline Maximum & 100 & 100 & 81.25 & 81.25 & 100 & \multicolumn{3}{|c|}{100} \\
\hline \multicolumn{9}{|l|}{$\begin{array}{l}\text { Insomnia } \\
(\mathrm{n}=22)\end{array}$} \\
\hline Median & 84.375 & 62.5 & 62.5 & 68.75 & 62.5 & \multicolumn{3}{|c|}{75} \\
\hline Minimum & 25 & 43.75 & 6.25 & 25 & 18.75 & \multicolumn{3}{|c|}{37.5} \\
\hline Maximum & 100 & 100 & 81.25 & 100 & 100 & \multicolumn{3}{|c|}{100} \\
\hline \multicolumn{9}{|c|}{$\begin{array}{l}\text { Table 6, The Spearman Correlation Test between Insomnia and WHOQOL-BREF and WHOQOL- } \\
\text { OLD }\end{array}$} \\
\hline \multirow{2}{*}{ Insomnia } & \multicolumn{8}{|c|}{ WHOQOL-BREF } \\
\hline & Physical & Psychological & Social & \multicolumn{5}{|l|}{ Environment } \\
\hline $\begin{array}{l}\text { Correlation } \\
\text { Coefficient }\end{array}$ & -0.518 & -0.159 & -0.117 & -0.106 & & & & \\
\hline \multirow[t]{3}{*}{ p-value } & 0.000 & 0.224 & 0.374 & 0.422 & & & & \\
\hline & \multicolumn{8}{|c|}{ WHOQOL-OLD } \\
\hline & $\begin{array}{l}\text { Sensory } \\
\text { Ability }\end{array}$ & Autonomy & $\begin{array}{l}\text { Past, } \\
\text { present, } \\
\text { and } \\
\text { future } \\
\text { activities }\end{array}$ & Participation & $\begin{array}{l}\text { Death } \\
\text { and } \\
\text { Dying }\end{array}$ & Intim & nacy & Total \\
\hline $\begin{array}{l}\text { Correlation } \\
\text { Coefficient }\end{array}$ & -0.257 & -0.049 & -0.019 & -0.074 & -0.226 & 0.015 & & -0.302 \\
\hline p-value & 0.047 & 0.711 & 0.888 & 0.573 & 0.082 & 0.912 & & 0.019 \\
\hline
\end{tabular}

Source: Primary Data, 2019

$(-0.302)$. Other study discovered that there was significant negative relationship between sleep disorders and quality of life (Tel, 2013).

This study had limitations. The use of the cross-sectional method makes the causal relationship between insomnia and quality of life cannot be determined. Other limitation was that the risk factors contributed to insomnia had not been studied.

\section{Conclusions}

It can be concluded that $36.7 \%$ elderly had insomnia. A negative correlation was discovered between insomnia and the quality of life in elderly even though the correlation was weak. In the future, the Public Health Center could give early interventions to insomnia in the elderly in order to prevent several consequences caused by insomnia and 
to enhance their quality of life. A further study should be carried out to analyze the risk factors contributed to insomnia.

We thank all the head and staff of six Public Health Centers in Bandung City to facilitate this study and all the elderly who participate in this study. We also thank Dr. Deni K. Sunjaya, dr., DESS who gave us permission for using the Winstep program version 3.73.

\section{References}

Boone, W. J. (2016). Rasch Analysis for Instrument Development: Why, When, and How? CBE Life Sciences Education, 15(4), 1-7.

Chhantyal, A., \& Rekha, T. (2017). Factors Associated with Insomnia Among Elderly of A Selected Community of Lalitpur. Journal of Gerontology \& Geriatric Research, 06(02), $1-7$.

El-Gilany, A.-H., Saleh, N., Mohamed, H., \& Elsayed, E. (2017). Prevalence of Insomnia and Its Associated Factors Among Rural Elderly: A Community-based Study. International Journal of Advanced Nursing Studies, 6(1), 56.

Gondodiputro, S., Wiwaha, G., Lionthina, M., \& Sunjaya, D. (2019). Reliability and Validity of The Indonesian WHOQOL-OLD Version: A Rasch Modelling. Unpublished.

Kim, W. J., Joo, W. T., Baek, J., Sohn, S. Y., Namkoong, K., Youm, Y., Kim, H. C., Park, Y. R., Chu, S. H., \& Lee, E. (2017). Factors Associated With Insomnia Among The Elderly in A Korean Rural Community. Psychiatry Investigation, 14(4), 400-406.

Mattis, J., \& Sehgal, A. (2016). Circadian Rhythms, Sleep, and Disorders of Aging. Trends in Endocrinology and Metabolism, 27(4), 192203.

Miner, B., \& Kryger, M. H. (2017). Sleep in the Aging Population. Sleep Medicine Clinics, 12(1), 31-38.

Morin, C. M., Belleville, G., Bélanger, L., \& Ivers, H. (2011). The Insomnia Severity Index: Psychometric Indicators To Detect Insomnia Cases and Evaluate Treatment Response.
Sleep, 34(5), 601-608.

Mukku, S. S. R., Harbishettar, V., \& Sivakumar, P. T. (2018). Insomnia in Elderly: A Neglected Epidemic. Journal of Geriatric Mental Health, 5(2), 84-93.

Purba, F., Hunfeld, J., Iskandarsyah, A., Fitriana, T., Sadarjoen, S., Passchier, J., \& et.al. (2018). Quality of Life of The Indonesian General Population: Test-retest Reliability and Population Norms of the EQ-5D-5L and WHOQOL-BREF. PLoS ONE, 13(5), 1-20.

Rodriguez, J. C., Dzierzewski, J. M., \& Alessi, C. A. (2015). Sleep Problems in the Elderly. 99(2), 431-439. https://doi.org/10.1016/j. mcna.2014.11.013.Sleep

Sateia, M. J. (2010). Introduction: History, Definition, andEpidemiology. In M. J. Sateia \& D. J. Buysse (Eds.), Insomnia, Diagnosis and Treatment (p. 5). Informa Healthcare.

Schober, P., \& Schwarte, L. A. (2018). Correlation Coefficients: Appropriate Use and Interpretation. Anesthesia and Analgesia, 126(5), 1763-1768.

Soósová, M. S. (2016). Determinants of Quality of Life in The Elderly. Central European Journal of Nursing and Midwifery, 7(3), 484-493.

Suzuki, K., Miyamoto, M., \& Hirata, K. (2017). Sleep Disorders in The Elderly: Diagnosis and Management. Journal of General and Family Medicine, 18(2), 61-71.

Tel, H. (2013). Sleep Quality and Quality of Life Among The Elderly People. Neurology Psychiatry and Brain Research, 19(1), 48-52.

Uchmanowicz, I., Markiewicz, K., Uchmanowicz, B., Kołtuniuk, A., \& Rosińczuk, J. (2019). The Relationship Between Sleep Disturbances and Quality of Life in Elderly Patients with Hypertension. Clinical Interventions in Aging, $14,155-165$.

World Health Organization. (1996). WHOQOL$B R E F$, Introduction,Administration, Scoring and Generic Version of The Assessment. Programme on Mental Health WHO.

World Health Organization. (2006). WHOQOLOLD Manual. WHO-European Office. 